\title{
Time to reconsider stem cell ethics - the importance of induced pluripotent cells
}

\section{Søren Holm}

The discovery of an alternative method of producing induced human stem cells will affect the ethical evaluation of human embryonic stem cell research

On 20 November 2007 two groups of researchers announced that they had independently managed to produce induced Pluripotent Cells (iPC) from human adult (ie not embryonic or foetal) somatic cells. ${ }^{12}$ The two groups used slightly different procedures, but both approaches involved overexpression of a group of four genes known to be actively expressed in human embryonic stem cells (hESC). The cells produced are very similar to human embryonic stem cells, they are pluripotent and they differentiate to specific cell types when treated according to protocols leading to that specific differentiation in hESC.

\section{WHAT ARE THE IMPLICATIONS OF THESE RESULTS FOR STEM CELL ETHICS?}

There seems to be at least two areas of debate and research where there are important implications and one area where there are none.

Let us deal with the area where these results have absolutely no implications first: the contentious debate about the moral status of the embryo. Nothing in these research results will or can affect the position of those who believe that they have good arguments showing either that the embryo has no moral status at all, or that the embryo has such significant moral status that it can never be purposely destroyed. For both groups the existence of an alternative to hESC has no implications for their basic position and no implications for whether hESC research should be pursued. For the first "no moral status group" the discovery of methods to produce iPCs might of course have implications for the relative funding of hESC research, but that is another matter.

Correspondence to: Søren Holm, Cardiff Law School, Cardiff University. Law Building, Museum Avenue, Cardiff CF10 3AX, UK, \& Section for Medical Ethics, University of Oslo, Oslo, Norway, holms@cardiff.ac.uk
It might mischievously be argued that the results show that every somatic cell is potentially an embryo thereby constituting a reductio of the moral status argument, because the methods allow the production of pluripotent cells from somatic cells, but that argument is fallacious. We have to beware of a possible equivocation on the term "embryonic" in embryonic stem cells. Embryonic stem cells are cells derived from embryos, not embryo cells. Although the embryo is made up of pluripotent cells it is only an ordered embryo and not a mere collection of pluripotent cells because it contains both cells with the potency of hESC and presumably iPC and cells with the potency to create the extraembryonic tissues.

The findings do have significant implications for stem cell ethics for anyone who thinks that there are good reasons for believing that embryos have some moral status, and that the destruction of embryos for research therefore requires some justification in terms of the likely benefits of that research. This seems to be the position underlying the legal regulation of hESC research in almost all jurisdictions where this kind of research is regulated. No country has regulation that is consistent with the view that embryos have no moral significance. And it is the promise of therapies for large groups of people that have persuaded legislatures to allow hESC research.

The discovery of a new alternative method of producing human stem cells for research, and eventually therapy that do not involve hESCs will, all other things being equal, make it less likely that pursuing a given goal through hESC research is necessary or the best way of pursuing that goal.

This is most obviously the case in relation to the research programme aimed at producing personalised stem cells through somatic cell nuclear transfer (SCNT) (sometimes called "therapeutic cloning"). The iPC research programme is aimed at achieving exactly the same ends as the SCNT programme, that is, cells that are immunologically identical to a particular person without destroying any embryos. Whereas SCNT research may therefore previously have been necessary to achieve the good end of personalised stem cell therapy, it is no longer necessary because there is now a competitor technology; and SCNT is arguably no longer even a preferable option given its low success rates $(0.7 \%$ in Macaques, the only primate where the technique has currently been shown to work ${ }^{3}$ ). In this context it is important to remember that given that there has not been successful reproductive cloning of any primate it is unknown whether hESC created by SCNT will actually have the same potency as other hESC, and the estimation of potency for iPC and SCNT derived hESC is hypothetical in both cases.

In general, any argument that incorporates a premise that a given ethically laudable goal-for example, therapies for many human diseases can only be obtained if $\mathrm{hESC}$ research in general, or a specific kind of hESC research is allowed or funded is now substantially more suspect than before the publication of the iPC results (for a general account of the problems with "hopeful arguments" see). ${ }^{4}$

The findings also have implications for the ethics of those areas of stem cell research that involve the creation of embryos from donated eggs. It is well recognised that the availability of eggs is very limited partly because egg donation is an invasive procedure very different from the donation of sperm and partly because it is difficult to get women to donate eggs without substantial payment or other kinds of compensation (eg, free IVF).

This makes these kinds of research "a feminist issue" in the sense that one aspect of these techniques only involves the interests of women. In so far as there is another equally effective method for achieving the same goals that do not put women at risk of exploitation or coercion there is a reason to prefer this other method. Let us accept for the sake of argument that there has not been a research programme of equal promise to hESC research, that is, the adult stem cell research programme is not equally promising. This has now changed with the first proof of principle of iPCs and the bar has therefore been raised for when it is justifiable to pursue research involving egg donation.

To sum up, the results published on 20 Nov 2007 should affect the ethical evaluation of hESC research for anyone who believes that that evaluation involves a balancing of the ethical value of embryos 
against the good that stem cell research might bring.

Competing interests: None declared.

Received 28 November 2007

Revised 28 November 2007

Accepted 28 November 2007
$J$ Med Ethics 2008;34:63-64. doi:10.1136/jme.2007.023903

\section{REFERENCES}

1. Takahashi K, Tanabe K, Ohnuki M, et al. Induction of Pluripotent Stem Cells from Adult Human Fibroblasts by Defined Factors. Cell 2007. DOl:10.1016/J.cell.2007.11.019
2. Yu J, Vodyanik MA, Smuga-Otto K, et al. Science 2007. DOl: 101126/science. 1151526

3. Byrne JA, Pedersen DA, Clepper LL, et al. Producing primate embryonic stem cells by somatic cell nuclear transfer. Nature 2007;450:497-502.

4. Holm S, Takala T. High hopes and automatic escalators: a critique of some new arguments in bioethics. J Med Ethics 2007;33:1-4. 